\title{
Violence on television - comparative overview of world experiences and Macedonian media practice
}

\section{Liljana Siljanovska}

Faculty of Language, culture and communication at South East European University, Tetovo, Republic of Macedonia

\section{Email address:}

1.siljanovska@seeu.edu.mk

\section{To cite this article:}

Liljana Siljanovska. Violence on Television - Comparative Overview of World Experiences and Macedonian Media Practice. Humanities and Social Sciences. Vol. 2, No. 2, 2014, pp. 38-46. doi: 10.11648/j.hss.20140202.15

\begin{abstract}
Television is the primary source of consuming informative contents on a daily basis. For that purpose, a lot of changes are being made in order to keep the attention of the audience that is influenced by these contents no matter whether the influence is direct or indirect. In this respect this depends on the communication content or credibility of the communicator, on the personality of the recipient and his position in the society as well as on the circumstantial conditions. Within experts and scientific circles, there are wide debates about the violence that is shown daily on television as constitutive part of many media contents, from the entertainment programs to journalist reporting which represents a kind of public information. Violence, as asocial emergence, represents a complex notion and is a very complex category by structure that includes the most different forms, shapes and ways of manifestation. This paper includes: the forms and types of violence on television through analysis of different thematic program contents of the national television stations in Republic of Macedonia, a comparative analysis of the European and worldwide experiences from the media space as well as the impact on separate categories and interest groups of the audience through interviews with citizens and media experts and analysis of cases form communication reality.
\end{abstract}

Keywords: Violence, Television, Influence, Impact, Children, Movies

\section{Introduction}

According to the Law on Audio and Audiovisual Media Services of Republic of Macedonia: "[1] Media are means for public information like: newspapers, magazines and other printed sources, radio and television programs, electronic publications, teletext and other forms of editorially shaped program contents which are published, that is to say broadcasted daily or periodically in a written form, sound or image, in a way that is available to the wider public."

Nowadays media are the most widespread and they have enormous power and influence. The media power is seen in the cultural climate that is being promoted through them. By the help of the media, the people can educate themselves, upgrade, inform etc.

Mass media also offer possibility and capability to use the information that will provide the people with more successful participation in public life. In every democratic society, there is a tendency to provide objective, complete and verified information.

However, the media very often impact people negatively, which has reflected on the violence that is widespread throughout the world and the social-political and cultural research studies show that this is a reflection of the violent contents in the media.

Television might be singled out from the mass media, which besides the informative role, at the majority of the public with the biggest percentage consisting of the youth also has educational function which may be divided into positive and negative. Positive through broadcasting cultural - educational and scientific shows and negative through broadcasting violent acts in the news, music videos as well as in the movies which occupy great portion of the program scheme on the TV screens and which the young people simply accept as normal.

The violence in media occurs in different contexts and shapes and it reflects differently on the viewers and that is why it is extremely difficult to make a correlation between the media audience and aggressive behavior of the individuals in everyday reality. The intensity of the media influence depends on the degree of their education, on their intelligence, on social - economic and political conditions, as well as on the experiential practice and the reality of life 
of the recipients.

Because the violence in the mass media is shown in different ways (news, sport, action movies, documentary movies, cartoons, war stories etc.), it is not possible to form global opinion about the influence itself. Academic and scientific - research public cannot yet differentiate which characters would influence badly that is to say which programs would have bad reflection on the people. According to some, that would be action movies, according to others that would be the stories themselves or the documentaries about wars or armed conflicts, advertisements for certain products, even the cartoons and scene layout of the stories which have educational character.

Hence, this paper intends to confirm several forms and types of violence that are shown through media contents which occur in the real world, that is to say the violence that is being shown in various ways through media is motivation for violent that is to say aggressive behavior.

\section{Television as Powerful Medium}

As a very important product of the development of communication technology after the invention of the printing machine, television changes forms and shapes of social reality, it creates new habits and valuable structures and it also changes the way of life. Television shapes, builds and at the same time segments and modifies the audience. With a bigger or smaller impact, this refers to the readers, listeners, film audience and as well as to the interest groups divided according to the interest in the different thematic contents. Defining its future according to the functional practices and effects on the mass audience shows that television has the privilege of the so called electronic public and also the privilege to create public opinion of the communication reality. Although in the era of post modernization and global technical- technological revolution, there are frequent debates that online information is faster and has greater interaction with the public, the television, at least for now, remains the most powerful medium by creating polyvalent relations towards its audience.

Within world frames, the process of integrating television networks is famous worldwide, but in Republic of Macedonia there are still large numbers of television stations that are with national concessions. The first Law on Broadcasting had a primary tendency to provide media pluralism of ownership aspect, but above all of the content aspect, although the media analyses show that media pluralism does not contribute to increased level of information.

Television has several functions: to inform, to entertain and to educate. In the development of the television as domestic that is to say family media, several broadcasts contributed, for example: the first human step on the moon, the murder of Kennedy, students' protests on Tiananmen Square - broadcasted 24 hours live. Today many world leaders find out the news from the media first, that is to say from television, and also many decisions, reforms and activities in the public, political, economic and cultural life are realized, stopped or highlighted under pressure from the public. Educational programs are a special challenge for every television, and from the audience aspect and its number, the media are extremely attractive for advertising as well.

[2] Several research studies have shown that the viewers mostly see the television as a source of information that is to say as the most credible source of news. Television news is faster, dramatic and followed by image. It should be known that journalism is news but television news at least for the Americans is show as well, so according to that it should attract audience. (Baran S. J., 2002, Introduction to Mass Communication, second edition, Chapter 9)

Even the best professionals, respecting the standards for objectivity, punctuality and authenticity cannot inform the audience if the audience itself does not take part in it, and besides the good content, the good image is also important for the television because the image often tells more that the word. In different cases, many professionals cross the ethic line and even create the place of the event. Sometimes, for the media literate person this could be acceptable argument, if the reporter is on the location of the event but does not have image of what had really happened (for example car accidents, some meetings and similar). But, it is for sure that the confidence of the audience in certain media will be questioned if there is not difference between fact and fiction, reality and illusion.

Media literate person should develop analysis strategies for the content that is being shown, making decisions where to draw the line, that is to say how to reject fabricated news and events.

Everyone who is trying to study television should know that there are differences in watching at the individual itself that is to say the recipient. This depends on the mood, company, place but also a question raises through which discourse the programs are being observed and analyzed.

In theoretical circles, the thesis that the texts and audience could be defined by the term impurity is more striking, but such qualifications might also cause misunderstanding. This term is an attempt to critically observe the television, not only because it is the most powerful medium that enters the lives of the people on a daily basis, but also because it substantially changes the understanding of the world and social reality through its messages and contents. Thus, the German author Hans Magnus Enzensberger (1970) notes that "in [3] Electronic media are far from purity, they are impure by nature, which is a part of their production force. The wish to draw a clear line, the avoidance of the deviations is anarchic and serves only those that seek safety" - concludes Enzensberger. (Enzensberger, H. M., Constituents of a Theory of the Media, 1970, p. 264)

\section{Violence on Television and Influence}

The violence has occurred since the emergence of the human kind. It is found in various forms and there are 
different reasons for its emergence. One of the reasons for the existence of violence in the real world, which is particularly significant in the postmodernist period, is the existence of mass media. The violence itself, which is being shown through them, reflects on the real world most often as means to solve the conflicts or as imitation of persons and characters with violent behavior.

As constitutive element of great number of media contents, this is present in the artistically created television production, but also in factual television production like documentary programs or journalist reporting for the current events.

The violence through media might have harmful impact on the whole audience but the children and youth are particularly subjected to this harmful impact because they have less developed abilities to tell the difference between reality and fiction. Among one of the many definitions for violence, the following can be singled out:

“... in [4] each open broadcast of a true threat from a physical force or authentic use of physical force, with or without weapons, with the intention to harm or intimidate human being. Violence also includes showing physically harmful consequences of a certain life being which occur as a result of unforeseeable violent means." (Broadcasting Council of Macedonia, 2000, Platform for children and youth protection from violence and pornography on television, page 11). United Nations often state that violence has different shapes. Violence occurs when somebody is using his or her force or position of power in order to harm somebody else intentionally, not accidentally.

- Violence also comprises threats for violence and actions that might cause injury or damage, as well as actions that actually cause injury or damage. The injury or damage might also be on somebody's psyche, general wellbeing and on health and body. Violence also comprises injury or damage which somebody intentionally has inflicted upon himself including suicide [5]. (Report of the Independent Expert for The United Nations Study on Violence against Children, 2006, p. 8)

Nevertheless, the numerous research studies are not always that consonant with each other and generally we could speak about two basic courses of opinions. According to one course, violence from the media has a direct and harmful impact on children because it influences their aggressiveness and that leaves permanent consequences even when they become adults. The second course of opinion first of all connects the negative influence with the context in which the violence is presented but also with the social environment of those that receive these media contents. Of course, within the frames of the above mentioned courses, there are numerous various considerations about the way of realization of the harmful influence, but at the same time there are several common opinions about the effects from the programs which show violence and which can be grouped into three general courses of behavior. The first course argues that it is possible to learn, that is to say accept the aggressive attitudes and behavior. The second course argues that in continuous contact with the violent contents in media products, a creation of insensibility towards violence could be expected and the third course argues that a fear to become a victim of violence could be increased.

\subsection{Negative Influence through Movies}

Movies which are being shown on television every day impact the youth very negatively. This is particularly for the enormous number of crime and adventure movies and movies where aggressiveness and violence dominate. Besides the negative context of the content, the primary dangers in that sense are the images of violence pervading the movies that are watched by the youth. Through the movies, observing the people that live in circumstances of thefts, huge number of murders and kidnappings, a syndrome of long term identification and projection with these characters occurs and this is the way that leads towards standpoint of treating the violence against children as usual (normal) appearance.

Research studies for the actions of the movie upon children's psyche show that the movie could also play one cathartic role. This could be done by movies which are well selected for the age of the viewers, but on the other side it is shown that the scenes of torture, kidnaps, robbers, pornography, movies which include people with superhuman skills and great number of murders are detrimental to children's psyche and play very negative role in the behavior of the young audience. The repetitive exposure of aggressive behaviors from the small screen, much bigger than in the real world, is strong enough to impact the opinions and behavior of the youth. In the best case, watching these movies increases the tolerance regarding the acts of aggression and violence.

Children most often copy the characters from certain movies and imagine themselves as main heroes which are violent. This reflects badly on the children, and being led by the violence from the movie, they start the 'street wars'. Violence can be seen right here. Also, resolution of conflicts that occur as a result of the different opinions and interests is done through violence which is more presented as a method for solving daily conflicts.

For example, great number of killings happened after the movie "Scream" as was the murder of a young girl in Belgium by a taxi driver that committed the crime wearing the same costume like the murderer in the movie. He admits to committing the murder because he was motivated by the movie [6]. (Magazine The Guardian, November 17, 2001).

\subsection{Negative Influence through Games}

"in [7] Game is a process where the children try to understand the reality in their own way. While they are playing, they are using their imagination and creativity and they work on creation of new ideas and understandings. But, when children imitate, they are trying to copy something that they had seen earlier." (Piaget, 1951, Play, Drams and 
Imitations in Childhood, p. 58)

As it was mentioned before, children and generally all people commit violence led by the violence in the media. They, in some way, imitate the characters from the movies, video games, and their behavior and that way they develop such anti-social i.e. aggressive behavior.

" in [8] Children, very often, are those that imitate the characters with violent behavior in their children games. However, a difference should be made between game and imitation. Although imitation may represent game, if the imitation is of violent character, it will have a bad reflection in the reality." (Carlsson-Paige, N., \& Levin, D. E., 1990, Who's Calling the Shots?: How to Respond Effectively to Children's Fascination with War Play, War Toys and Violent TV, p. 22)

Effects form violence in the media reflected in the real world are present and can be seen in the analysis of the content of some magazines, for example: Michael Rayan committed mass murder because he thought he was a character from the video game Rambo, then Jamie Bular, young girl was killed by children who were playing video games with violence [9]. (Albertazzi, D., Cobley, P., 2013 The Media: An Introduction, p. 358)

Because of these events, certain countries widely restrict renting of video games and movies as well as certain programs shown through the media. But, it cannot be claimed for sure that the authorized institutions and the organizations authorized for restriction will contribute to decrease or possibly to halt the broadcasting of violence in the media. It can be concluded that lately certain countries have regulated this in the national media regulations with specific provisions for warning for different categories and also for the time of broadcasting.

\subsection{Negative Influence through TV Commercials}

In the latest divisions in the market there are many target groups: women, men, children, young, retired, rich, poor.... Within the norms of economic propaganda, series of rules regarding the audience especially children take place. Children are especially subject to great influences from the media because they have less developed abilities to tell the difference between reality and fiction.

The aim of the advertisements is to present well certain product which will attract the citizens' attention with intent to increase its consumption. But in many cases the media make mistakes in the implementation of the advertisements, especially in the visual organization of the communication message where famous people and favorite show business characters take part.

There are huge numbers of commercials which oftentimes unnecessarily involve children and the aim of these commercials is to convey the message to buy the product, neglecting the feelings of the viewers especially of the children.

The segment of the communication reality with regards to TV commercials designed for the youngest, commercials that stimulate domestic violence, violation of women's rights as well as violence and violation of the people with disabilities should be particularly pointed out.

- For example a commercial for soft drink, in which a child takes part being treated as a ball. In front of the eyes of the parents, the child is being thrown out and hit against a wall which represents inconvenient scene especially if the commercial is being watched for the first time. With every next viewing of the commercial, the television audience is getting used to such scenes, which are similar to what is a part of a daily TV program.

- Another example - washing powder commercial where children are hanged on a wire and feel dizzy from centrifuge, which some people might find funny but on the other side, the commercial might create revolt because of the possibility to motivate violence.

- Commercial for coughing syrup where the wife hits the husband on the back with several objects with an aim to help him cough. This commercial might stimulate domestic violence.

- Commercial against abortion where the woman's rights are violated and where the doctor congratulates the father for the successfully committed murder of a male fetus which could have grown into a healthy male child. There were a lot of reactions after the commercial was broadcasted which led to ban the part of the commercial that mentioned murder. Besides violating women's rights, this commercial stimulates violation only by mentioning murder.

- The advertisement for proper parking, where the driver after not being able to find parking space for his car finds space designated for disabled people and parks his car there, takes a saw out of his car, cuts his leg and immediately after that wakes up from the bad dream. This commercial is not only morbid and motivates violence but is also insulting for the people with disabilities.

It could be concluded from these examples that commercials might motivate formation of bad habits. The syndrome of identification and projection with the main characters in the commercials is multiplied in the consciousness and behavior of the audience in different situations in practice. The impressive posing of the convincing component for a certain product or service through nonverbal communication oftentimes loses the point of statement of the message or it is secondary regarding the informative elements which have an aim to stimulate the consumers' cognitive dimension and consciousness in order to cause proper action - i.e. buying the product or using the service of a commercial character.

\section{Analysis of Research Studies of Examples for Negative Consequences}

In Republic of Macedonia it is not calculated exactly how much, but in several western countries (for example in 
France) the children aged 8-13 spend, on average, more hours in front of the television appliance than at school. Research studies show that the Americans calculated that up to 17 years one child watched more than 18.000 murders on the screen.

According to the research of Sasho Ordanovski (media analyst) at the Platform for Children and Youth Protection from violence on television in Republic of Macedonia, significant examples which left severe consequences have been singled out:

"in [10] on February 29, 2000, Dedric Owens fatally shot Kayla Rolland in the small place Flint, Michigan in the United States of America with one shot fired from his uncle's 32 caliber semiautomatic handgun. In country where hundreds of murders happen every day, this probably was not huge news, but the news was that James Owen was 6 year old and killed his classmate who was also 6 year old. With this, another sad world record was set because until then the youngest murderer in the United States of America had been 10 years of age". During the investigation regarding the manslaughter that caused a huge debate in the USA, the father of the killer stated that his son had spent most of his time watching video-movies and television with violence. (Broadcasting Council of Macedonia, 2000, Platform: Children and Youth Protection from violence and pornography on television, page 6)

" in [11] Encouraging the children to compare the television stereotypes with their own experience, makes it is possible to separate the real world from television". (Davis, 1991, Five important ideas to teach your kids about TV, p. 17 )

The research conducted by UNESCO in 1996 and 1997 covered five thousand children at the age of twelve from 23 different countries. The research was conducted in order to find the connection between violence in the media and aggressive behavior of the children [12]. (Groebel, J., 1999, The Unesco global study on media violence, p. 5)

In Belgium, one boy aged 12 beat a child aged 7-8 years, where if an adult had not intervened the child would have sustained severe physical injuries. When asked why he was beating the child so much, the boy answered that he wanted to see how much the child could physically endure beating. It is for sure that the boy had acquired wrong views for life. [13] (Broadcasting Council of Macedonia, 2000, Platform: Children and Youth Protection from violence and pornography on television, page 23)

The latest data in Great Britain show that above $60 \%$ from the children have their own television appliances in the children's rooms, while in France 500 thousand program hours on different channels and cable televisions are broadcasted annually. Compared to them, the Macedonian television broadcasts between 10 to 12 thousand program hours annually.

According to UNESCO research, violence in media mostly reflects on children and this reflection is getting bigger and bigger every year in the real world. Most often the children who live in urban environments and who go to school and behave well are limited in watching television because they spend most of the day conducting other activities like hanging around, doing sports, studying, doing homework, reading etc. Watching television is not the most important media in the lives of these children and that is why the aggressive behavior is not present. On the other side, children who live in environments where the violence is present as a part of the real world, children who don't go to school, children who are not limited in watching television and other media that show violence, demonstrate more aggressive i.e. antisocial behavior. According to them, the violence is the best way to resolve the conflict and this thinking derives from the mode through which the violence is being broadcasted. However, this antisocial behavior, besides the fact that it derives from the violence in media, is also a result from disintegrated family, feeling of aversion towards the others etc.

From the analysis of the indicated research studies, it could be concluded that great part of the conflicts that occur in the real world could be a result from the violence broadcasted through media.

\subsection{Analysis of Violence on Television in Macedonia}

Violence which is shown on television is present in great proportions. Its broadcasting might be in different shapes, physically or psychologically. According to the United Nations Report on violence against children, there are the following types of violence [14]:

$>$ Physical violence: pinching, scratching, tripping somebody up, pulling clothes, pushing and grabbing, thrusting at somebody, hitting with an object, fights, inflicting injuries with fire arms, inflicting injuries with cold weapon

$>$ Psychological violence: intimidation, insulting, swearing, mocking, threatening, carrying weapons, extortion and coercion, damaging other's objects, stealing

(Report of the Independent Expert for The United Nations Study on Violence against Children, 2006, p. 21)

Analysis of the content of thematic zones of several national television stations in Macedonia and manner of broadcasting of certain program contents in prime time when television is mostly watched shows that there is an appearance of the above mentioned forms of violence.

Particularly noteworthy is the analysis of the "Macedonian Stories" and "The Adventures of Clever Peter" broadcasted on two Macedonian television stations in the afternoon hours. Unlike the previous Macedonian folk tales, where according to the interviews of the older audience they were eager to watch them in their time because despite the entertaining had also educational character, in the contemporary Macedonian stories, besides the didactical message conveyed in each story, there is some form of violence in almost each of them. For example: insulting, thrusting at somebody, intimidation, mocking, pulling clothes and threatening are forms of violence that are noticed by some of the interviewed citizens, according 
to which, although not that scary and threatening, they are still a kind of violence. In The Adventures of Clever Peter besides these forms of violence, fighting, hitting with objects, curses and even sexual harassments are shown [15]

Several Macedonian television stations were monitored during the analysis of the media and it was concluded that all televisions had included violent contents. Violence on televisions has been shown in various media programs:

$>$ in informative news (great amount of broadcasted articles contained news about some violence)

$>$ in feature films (especially broadcasted during weekends included many forms of violence)

$>\quad$ in cartoons designed for the youngest (where violence should not be shown at all, there were scenes with fights, thrusting at somebody, tripping up)

$>\quad$ in Turkish series (which are shown in prime time from 19 to 22 o'clock there were particularly emphasized forms of violence, out of which inflicting injuries with weapon can be especially singled out)

$>\quad$ in advertisements or economic propaganda messages (where forms of violence such as hitting with objects, intimidation, mocking are also shown)

Television analyses and presentation of violence in the programs indicate that number of educational shows and programs that can be of benefit to everyone is becoming smaller. The broadcasting of more such contents will increase awareness among audience and will reduce the occurrence of violent contents on television.

\subsection{Comparative Analysis in the World}

Comparative analysis of violence on television around the world, suggest that this phenomenon is present everywhere in the media. According to the reports of the foreign television "Parents TV", concerns about the impact of the violence on television on society is almost as old as the medium itself. Back in 1952, representatives of the U.S. White House gave recommendations for research on impact of television violence and concluded that: "in [16] The television broadcast industry was perpetuator and a deliverer of violence." (US Senate Committee on Commerce, Science and Transportation, Marketing Violence to Children, 106th Cong., 2nd sess., 13 September, 2000th). Another research on violence on television was conducted in 1972 and concluded that it was " in [17] Factor which contributes to the increase of the violent crime and antisocial behavior. "(Mifflin, Lawrie. Many Researchers Say Link is Already Clear on Media and Youth Violence, The New York Times 9 May 1999)

Over the years, there have been literally hundreds of studies that have examined the relationship between media and violence in real life, and the results were summarized in a joint statement signed by the leaders of the first six public health organizations in the nation, including the American Academy of Pediatrics, American Psychological Association and the American Medical Association:

"in [18] More than 1000 studies with particular emphasis on the cause-and-effect connection between media and violence and aggressive behavior in some children, based on over 30 years of research, concluded that watching violence as a form of entertainment can lead to increased aggressive attitudes, values and behavior, particularly in children. "(Joint Statement on the Impact of Entertainment Violence on Children, Congressional Public Health Summit, July 26, 2000)

According to the analysis of this foreign television, children averagely spend 25 hours a week watching television, which is more time than they spend in school. Television can have deep influence in shaping values, attitudes, perceptions and behaviors among youth.

Analysts from Parents TV [19] have researched all the shows broadcasted in prime time on the major television networks (ABC, CBS, Fox, NBC, UPN, CB). Total of 400 hours of the program were analyzed, while television broadcasts of movies, news and sports programs were not included in this analysis. Analysts reviewed all programs that had shown violence. Somewhere there were mild forms of violence including: threats of violence, mayhem, pyrotechnics (fires, explosions, accidents), deaths caused by fights with fists and martial arts. Apart from these forms of violence, there were extreme examples of violence including: the use of weapons, showing blood, graphical presentations of the dismembered body, showing deaths and torture [20]. (Parents Television Council State of the Industry reports, online).

According to statistical data, generally, the violence increased in the period between 1998 and 2002. Combined from all television networks, violence was $41 \%$ higher in 2002 than in 1998, around 20:00 in time when the whole family are watching television together. It can be singled out that UPN and Fox had the highest recorded rate of violence in 2002, around 20:00, and $A B C$ had the largest increase in the broadcast of violence to $1400 \%$ from 1998 to 2002 . CB and KBS broadcasted violence the least. It was found out from the research that violent content was shown more in the later hours of the prime time [20]. (Parents Television Council State of the Industry reports, online)

Examples of program schedule and content of several foreign televisions which broadcast violence in prime time are indicated below [20]:

$>$ Diagnosis Murder 11/05/98 9:00 p.m. CBS (broadcasting murder committed by cold weapon)

$>\quad$ NYPD Blue -- 11/17/98 10:00 p.m. ABC (scenes with blood and murders)

$>$ Buffy the Vampire Slayer -- 11/14/00 8:00 p.m. WB (scenes of demons fighting)

$>\quad$ Boston Public - 11/13/00 8:00 p.m. Fox (broadcasting of fights)

$>\quad$ City of Angels - 11/02/00 9:00 p.m. CBS (attacks scenes)

$>$ Providence - 11/01/02 8:00 p.m. NBC (broadcasting of murders committed by weapons)

Thus we can compare that foreign televisions also show scenes of violence in prime time when the whole family are in front of the screens. In the abovementioned program 
schedule from 5 different televisions it can be seen that violent contents are broadcasted at 20:00 and at 21:00, which is considered as prime time, and similar content might be noticed also at 22.00. Although this term is not considered prime for children, there is a danger that they may be exposed to watching violent content.

\subsection{Legislation and Problem Resolution from Judicial and Ethical Standpoint}

There are several ways to prevent i.e. mitigate the impact of the media i.e. the violence that is shown through television on children. First of all, it is the domestic education. Living in a stable family gives quite good results. Parents often need to talk to their children about what they like from those programs on television, but above all, whether they think the characters from the television behave like the people in the real world. They should ask the children to compare their experience to the behavior of the characters, the characters that appear in the media as violent. The purpose of all this to make the children ask themselves whether they should copy this behavior, i.e. whether they should behave like that.

Encouraging children to compare television stereotypes with their own experience can lead to the possibility to separate the real world from television [11]. (Davis, Five important ideas to teach your kids about TV, 1991, p. 17) Good parenting is the best defense against the impact of media violence on children.

In fact Dr. Ronald Federici, (2003) child and family psychologist, believes that: " in [21] Children and young people can avoid the bad influence of media violence on them only if they are educated and brought up in an environment where they will gain a strong character and strong moral standards with the help of which they can tell the difference between reality and fantasy. "(Federici, R., S., 2003, Help for the Hopeless Child: A Guide for Families, p.168)

But it is not possible to determine which violence that will be shown will reflect well or badly on the people, viewers i.e. recipients of information and how they will react to it. It cannot be determined what people might watch and what they may not. Children could be controlled but not adults. Each individual has a different view and approach to what he or she receives as information from the media and that does not necessarily mean that it will reflect badly on the person. If the person is rational and aware, he knows how to assess and decide on his own for his behavior despite the impact of television. But for individuals who live in dysfunctional families, who have impaired mental health, who suffer from depression or have some other kind of problem, there may be a danger that the violence shown on television might have negative impact or encourage bad behavior.

Part of the violence shown in the media is information about events in the world, such as information about the war, about the victims, about religious conflicts, etc. Not always these cases of violence reflect badly on the viewer.
This, as previously mentioned, depends on the strength of character of the person who is actually the viewer, on his knowledge, education, intelligence level, the environment in which he lives, the stability of the family and many other aspects of the society in which he lives.

\section{Legislation and Problem Resolution from Judicial and Ethical Standpoint}

The new Law on Audio and Audiovisual Media Services in Republic of Macedonia includes a paragraph that provides for the protection of minors. According to Article 61:

"in [1] (paragraph 1) Providers of audiovisual media services shall not broadcast audiovisual or radio programs that may seriously harm the physical, mental or moral development of the minors, particularly programs that contain pornography or unjustified violence." The prohibition in paragraph (1) of this article also applies to other programs that could possibly harm the physical, mental or moral development of the minors, except where the provider of audiovisual media services has ensured that their broadcast or repeated broadcast would be in certain time period or has applied certain technical measure so that the minors, at the period of broadcasting or repeated broadcasting, will neither hear nor watch those programs in the usual way. When such programs are broadcasted or repeated in a form which is not coded, the provider of audiovisual media services shall, prior to broadcast, ensure earlier acoustic warning or opportunity to be recognized with the help of visual signs during their duration.

Thus, we can conclude that the violence on television may not be broadcasted and this issue can be legally solved But unfortunately not all media respect the legal provisions. To prevent this occurrence, except the media that should have a major role in preventing the emergence of violence, the society and social environment must also take part. For example, inclusion of parents in acquiring media literacy among children, then teachers through education in schools as well as taking measures to develop awareness among children and youth.

In 1996, the Assembly of the Council of Europe adopted a Recommendation on a European Strategy for Children, which emphasizes that the countries should encourage the media in promoting children's rights for a healthy and balanced development, and especially to encourage the media to remove the violence and to show positive social values in products designed for children [22]. (Council of Europe, Recommendation no. 1286 of the European strategy for children, 1996, p. 65)

When talking about protection from the negative effects of violence on television i.e. about appropriate measures which are limiting by its content or mean prohibition, the basic starting points are located in two documents adopted in 1989 : "The European Convention on Transfrontier Television" including the Article 7 which is of great importance and talks about protection of children and 
young people, was adopted by the Council of Europe and "Television without Frontiers" Directive adopted by the Member States of the European Union . According to Article 7, all parts of the program in terms of its presentation and content will respect human dignity and fundamental rights of others. The program shall not: a) be contrary to morality and contain pornography ; b) represent violence without reason, nor initiate racial hatred [23]. (European Convention on Transfrontier Television , 1989, Article 7 Responsibilities of the Broadcaster, p . 5 ). In fact, it was made clear that all the programs that are likely to be harmful for the physical, mental or moral development of children and youth, will not be broadcasted at a time when it is probable that this part of the audience will see this program.

Due to the increase of violence in reality reflected by the violence in the media, significant measures are being taken to prevent such rapid growth. These measures are covered in schools through special programs with special media education in form of media literacy, but primarily through communication and parental education. These measures are used to protect the children and all people from violence in the real world which is transformed by violence in the media, especially to remove the possible occurrence of anti-social i.e. aggressive, violent behavior.

" in [24] Media literacy is more than a tool to combat violence shown in the media. The person who is media literate has a capacity i.e. is qualified to communicate in all media forms, and to understand, analyze and evaluate personalities, words and sounds that compose our temporary mass media culture. The knowledge and application of this media literacy reduces the percentage of violence in the real world as a transformation of the violence shown in the media. Violence as a way to resolve conflicts is reduced from $17 \%$ to 6,9\% "(Thoman, 1995 , Media violence: The search for solutions, p. 48 )

\section{Conclusion}

Television as a powerful medium has a profound impact on viewers. Besides the positive effects on the development of young people, it can cause many negative effects by showing the violence that affects the formation of bad habits and behavior among youth. Broadcasting various forms of violence may direct negative and misleading messages. Television broadcasted violence may leave the most negative consequences on children, but it can also influence the adults, depending on their character, educational components, financial status and their physical condition. Violence against women shown on television, through films, TV commercials or documentaries based on true stories with similar occurrences could have negative impact particularly in families with a disturbed family system or in families where people with impaired mental health live. At the same time, at this type of conditions, violence against the elderly and domestic violence can also have impact and such cases are shown daily in the media, especially on the informative television news about events in Macedonia and wider.

To combat this phenomenon, there should be involvement of all relevant agencies and institutions which, according to the law, will implement all necessary measures for protection. Also there is a need for a large involvement in the development of media literacy among people that will help to assess whether that content is negative and how it will affect the audience. When the audience is able to judge which content is good, and which is not, the negative consequences of the impact of television on them should be reduced. As a precaution, the involvement of the parents is of significant importance, because they will influence their children and how they will receive media messages through educational process.

The school i.e. the teachers should influence students through the educational process, creating more projects and conducting research for media, so that the students themselves become able to distinguish between what is good and what is not. What content they should watch and which to ignore.

On the other hand, the Broadcasting Council should introduce specific measures which will be implemented for the most effective protection of children. The measures should include regulation of program schedules or time zones in which contents with violence will be broadcasted, and the program which will be assessed as inappropriate shall not be broadcasted at time when the children and youth probably watch TV. No matter if the program is going to be rescheduled, it should be labeled even it is broadcasted later from 22:00 or 24:00 pm.

Apart from these precautions, it is also necessary to influence the adult audience so it will clearly be emphasized before the beginning of the program with violent content that it is recorded content in which scenes are fictional, that the people are actors not real characters, that is not according to a true story etc. This kind of warning about the content that follows, can be seen on foreign television "Discovery" before the beginning of the show "Ultimate survival", a documentary which shows examples of surviving on a mountain, island or in nature where there are not settlements and it is difficult to find food and water, as well as basic conditions to survive. Such warnings prior to broadcasting some disturbing contents can visibly reduce the negative influence imposed by television stations and thus also affect the older category of viewers.

\section{References}

[1] Law on Audio and Audiovisual Media Services of Republic of Macedonia http://www.znm.org.mk/drupal7.7/sites/default/files/PropisNacrtZakonZaMediumi.doc

[2] Baran S. J, 2002, Introduction to Mass Communication, (2nd ed.) Chapter 9, New York: McGraw-Hill

[3] Enzensberger, H. M., 1970, Constituents of a Theory of the Media, p. 264, New Left Review December 
[4] Broadcasting Council of Macedonia, 2000, Platform: Children and Youth Protection from violence and pornography on television. Skopje, March 29th 2000; p. 11; www.srd.org.mk

[5] Report of the Independent Expert for The United Nations Study on Violence against Children, 2006, p. 8 http://www.beznasilstvo.mk/images/stories/time_for_change /documents/VIS_UNStudy_on_Violence_Child-friendly.pdf http://www.beznasilstvo.mk/mk/vreme-e-zapromena/vreme-e-da-razbereme-sto-e-nasilstvo

[6] Magazine The Guardian, November 17, 2001 Magazine The Guardian,

http://www.theguardian.com/theguardian/2001/nov/17/week end7.weekend9

[7] Piaget, 1951, Play, Drams and Imitations in Childhood, p. 58, London: Heinemann

[8] Carlsson-Paige, N., \& Levin, D. E., 1990, Who's Calling the Shots?: How to Respond Effectively to Children's Fascination with War Play, War Toys and Violent TV, p. 22 Gabriola Island: New society

[9] Albertazzi, D., Cobley, P., 2013 The Media: An Introduction, p. 358, London: Routledge

[10] Broadcasting Council of Macedonia, 2000, Platform: Children and Youth Protection from violence and pornography on television. Skopje, March 29th 2000; p. 6 www.srd.org.mk

[11] Davis, J F (1991), Five important ideas to teach your kids about TV, Media \& Values p. 17

[12] Groebel, J., 1999, The Unesco global study on media violence, p. http://unesdoc.unesco.org/images/0011/001178/117881e.pdf

[13] Broadcasting Council of Macedonia, 2000, Platform: Children and Youth Protection from violence and pornography on television. Skopje, March 29th 2000; p. 23; www.srd.org.mk

[14] Report of the Independent Expert for The United Nations Study on Violence against Children, 2006, p. 21 http://www.beznasilstvo.mk/images/stories/time for change /documents/VIS_UNStudy_on_Violence_Child-friendly.pdf

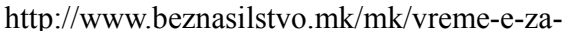
promena/vreme-e-da-razbereme-sto-e-nasilstvo

[15] Official website of the NGO "Peter Pan" - Skopje for the project "Active Participation and Youth Networking for research and action on the subject of violence". http://povrzuvanje.blogspot.com/2008/02/blog-post_26.html

[16] US Senate Committee on Commerce, Science and Transportation, Marketing Violence to Children, 106th Cong., 2nd sess., 13 September, 2000th

[17] Mifflin, Lawrie. (1999), 9 May,"Many Researchers Say Link is Already Clear on Media and Youth Violence." The New York Times

[18] Joint Statement on the Impact of Entertainment Violence on Children, Congressional Public Health Summit, July 26, 2000 http://www.aap.org/advocacy/releases/jstmtevc.htm

[19] Official website of the television Parents TV; http://www.parentstv.org/ptc/publications/reports/stateindust ryviolence/main.asp

[20] Parents Television Council State of the Industry reports, online.

http://www.parentstv.org/ptc/publications/reports/stateindust ryviolence/exsummary.asp

[21] Federici, R., S., 2003, Help for the Hopeless Child: A Guide for Families, p.168 Alexandria, VA: Federici and Associate

[22] Council of Europe, Recommendation no. 1286 of the European strategy for children, 1996, p. 65; Official Document of the Council of Europe: http://www.coe.int/t/dghl/standardsetting/family/Achieveme nts\%2008_08.pdf

[23] European Convention on Transfrontier Television, 1989, Article 7, Responsibilities of the Broadcaster, p . 5; Official document of Council of Europe: http://conventions.coe.int/Treaty/en/Treaties/Html/132.htm

[24] Thoman, E. (1995). Media violence: The search for solutions. The Momentum, 26 (1), p. 48. 